\section{A DISPUTA PELO FUNDO PÚBLICO NO FINANCIAMENTO E GASTO COM ESPORTE NOS GOVERNOS LULA E DILMA}

THE DISPUTE FOR PUBLIC FUNDS IN SPORTS FINANCING AND

SPENDING DURING THE LULA DA SILVA AND ROUSSEFF

ADMINISTRATIONS C

\section{LA DISPUTA POR EL FONDO PÚBLICO EN LA FINANCIACIÓN Y GASTOS EN DEPORTE EN LOS GOBIERNOS LULA Y DILMA C}

doi) https://doi.org/10.22456/1982-8918.99241

\footnotetext{
iD Fernando Henrique Silva Carneiro*<fernandohenriquesc@gmail.com>

Marcelo Paula de Melo** <marcelaomelo@gmail.com>

Nadson Santana Reis ${ }^{* * *}<$ nadsonsr@hotmail.com>

Fernando Mascarenhas ${ }^{* * *}<$ fernandom@unb.br>
}

\footnotetext{
*Instituto Federal de Goiás. Inhumas, GO, Brasil.

** Universidade Federal do Rio de Janeiro. Rio de Janeiro, RJ, Brasil.

***Universidade de Brasília. Brasília, DF, Brasil.
}

\begin{abstract}
Resumo: Este artigo objetivou compreender a disputa pelo fundo público no âmbito do financiamento e gasto com esporte nos Governos Lula e Dilma. A pesquisa, de caráter qualitativo, se apoiou em levantamento documental sobre as fontes de financiamento e o direcionamento do gasto com esporte de 2004 a 2015. Tais informações foram coletadas no Portal Transparência no Esporte, no SIGA Brasil e nos Demonstrativos dos Gastos Tributários de Bases Efetivas da Receita Federal do Brasil. Os dados apontam que o financiamento e o gasto com esporte nos Governos Lula e Dilma envolveram diferentes interesses econômicos, sociais e políticos que, por seu turno, se atrelaram às diferentes fontes de financiamento orçamento, extraorçamento e gastos tributários - e influíram no direcionamento do gasto - Esporte de Alto Rendimento; Esporte, Educação, Lazer e Inclusão Social; Infraestrutura; Megaeventos Esportivos; e Gestão.
\end{abstract}

Palavras-chave: Estado. Política Pública. Financiamento governamental. Transparência de gastos.
Recebido em: 27-12-2019

Aprovado em: 12-07-2020 Publicado em: 12-08-2020

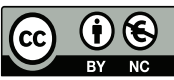

Este é um artigo publicado sob a licença Creative Commons atribuição Não Comercial 4.0 (CC BY-NC 4.0).

eISSN: 1982-8918 


\section{INTRODUÇÃO}

O fundo público é um elemento essencial para o Estado. Ele, por um lado, capta recursos das diferentes classes sociais, e, por outro, direciona-os para a intervenção estatal em diversos campos da vida social, com vistas, sobretudo, a viabilizar as condições concretas de dominação burguesa.

Desta forma, o fundo público representa a "[...] punção compulsória - na forma de impostos, contribuições e taxas - da mais-valia socialmente produzida, ou seja, é parte do trabalho excedente que se metamorfoseou em lucro, juro ou renda da terra e que é apropriada pelo Estado para o desempenho de múltiplas funções." (BEHRING, 2010, p. 20).

Athayde (2014a, p. 639) assevera que "[...] as disputas hodiernas que envolvem a repartição do fundo público sintetizam - no espectro político e social - a luta de classe contemporânea". Nesses termos, a disputa da burguesia e dos trabalhadores pela participação em sua distribuição tem levado o Estado e, consequentemente, o fundo público a atuar tanto para a reprodução do capital, quanto da força de trabalho, ainda que em menor grau e desde que não represente risco à estrutura e hegemonia da burguesia sobre o conjunto dos trabalhadores.

A disputa pelo fundo público e a configuração dos Governos Lula e Dilma guardam relação direta com o estabelecimento de prioridades em relação às políticas públicas, dentre elas a esportiva. O objetivo desse texto é, portanto, compreender a disputa pelo fundo público no âmbito do financiamento e do gasto com esporte nos Governos Lula e Dilma. Isso porque, o financiamento e gasto com esporte corresponde a uma chave interpretativa importante para a compreensão da materialização da política esportiva e de suas prioridades. Além disso, por meio daqueles, é possível identificar os diferentes interesses e agentes que disputaram e/ou influenciaram o fundo público do esporte entre os anos de 2004 e 2015.

A justificativa, para tanto, reside no fato de que faltam estudos que analisem a totalidade do financiamento e gasto esportivo federal, a despeito de trabalhos sobre o orçamento federal (CASTRO, 2016; MASCARENHAS, 2016; TEIXEIRA, 2016; CARNEIRO et al., 2019a; CARNEIRO; ATHAYDE; MASCARENHAS, 2019), as estatais federais (PEREIRA, 2017) e os gastos tributários (MATIAS et al., 2015; CARNEIRO et al., 2019b). Dessarte, falta uma análise de conjunto sobre a disputa pelos recursos do esporte.

Esse estudo, de caráter qualitativo, se apoiou em levantamento documental referente ao período de 2004 a 2015, uma vez que se considera a publicação dos Planos Plurianuais (PPA) dos Governos Lula e Dilma. Isso porque o PPA exerce papel fundamental na gestão pública, oferecendo diretrizes para as políticas públicas que acabam tendo reflexo direto sobre o fundo público.

A coleta de dados foi realizada no Portal Transparência no Esporte para os dados sobre o financiamento e gasto com esporte. Ademais, utilizou-se dados do SIGA Brasil (SENADO FEDERAL, 2019) e dos Demonstrativos dos Gastos Tributários de Bases Efetivas (RECEITA FEDERAL DO BRASIL, 2019). A análise dos dados tem 
como referência a metodologia desenvolvida por Carneiro e Mascarenhas (2018), sobretudo no que tange aos indicadores fontes de financiamento e direção do gasto. O primeiro está associado à discussão sobre a origem dos recursos e o segundo está preocupado com o direcionamento desses recursos (programas, projetos e ações).

Os dados financeiros foram deflacionados pelo Índice Geral de Preços - Disponibilidade Interna (IGP-DI), calculado pela Fundação Getúlio Vargas, a preços de dezembro de 2015, haja vista a necessidade de atualizar os valores para comparações longitudinais, eliminando os efeitos da inflação e da variação cambial da moeda brasileira.

A seguir, apresentamos uma breve análise dos Governos Lula e Dilma e de suas políticas esportivas, logo depois apresentamos e discutimos os dados sobre as fontes de financiamento do esporte e o direcionamento do gasto, encerrando com as considerações finais.

\section{A POLÍTICA ESPORTIVA DOS GOVERNO LULA E DILMA}

Marcado por contradições, o Governo Lula foi qualificado como uma administração neoliberal (COUTINHO, 2010; OLIVEIRA, 2010; BOITO JÚNIOR, 2012; PINTO, 2015), ou mesmo pós-neoliberal (SADER, 2013), caracterizada pela presença do lulismo ${ }^{1}$ e de um reformismo fraco (SINGER, 2012), com uma perspectiva (neo)desenvolvimentista ${ }^{2}$ (BOITO JÚNIOR, 2012; PINTO et al., 2016). Já Dilma, eleita em 2010, teve sua vitória creditada ao ex-presidente Lula (ANDERSON, 2011; SINGER, 2012).

Para Singer (2015), no Governo Dilma pode ser identificado como um ensaio desenvolvimentista sem êxito, já que o cenário econômico mais amplo era desfavorável e faltava a seu governo governabilidade e articulação política para tanto (PINTO et al., 2016). Reeleita em 2014, já em 2015 inicia a articulação de forças regressivas e reacionárias para seu impeachment - um processo dirigido pelo capital internacional e pelo setor da burguesia brasileira a ele associado, contando com apoio ativo da fração superior da classe média (BOITO JÚNIOR, 2017). Assim, seu impedimento ganhou força e se efetivou em meados de 2016.

No que tange à política esportiva, o Governo Lula trouxe importantes inovações. A primeira delas foi a constituição do Ministério do Esporte (ME) ${ }^{3}$. De início, sua prioridade teria sido o esporte como direito, elemento que foi substituído pela pauta dos megaeventos esportivos (ATHAídE, 2014b).

Ademais, as ações de seu governo envolveram, dentre outras coisas, a realização das Conferências Nacionais do Esporte (CNE) e o fortalecimento do financiamento do esporte, criando, para tanto, diferentes fontes de financiamento, das quais a Lei de Incentivo ao Esporte (LIE) e a Lei da Timemania são exemplos (CARNEIRO, 2018). Entretanto, é notório a grande influência e o protagonismo das

\footnotetext{
1 Para Singer (2009) lulismo expressa um fenômeno de representação de uma fração de classe que, embora majoritária, não consegue construir desde baixo as suas próprias formas de organização.

2 Boito Júnior (2012) caracteriza o (neo)desenvolvimentismo como o crescimento econômico do capitalismo brasileiro com transferência de renda, porém sem romper com o modelo neoliberal.

3 A criação deste se deu pela necessidade de acomodar o Partido Comunista do Brasil (PCdoB) à nova estrutura ministerial, em 2003.
} 
entidades de administração esportiva na política esportiva nacional (CASTELLANI FILHO, 2009), elemento que se fez bastante presente nos governos analisados.

A política esportiva dos Governos Lula acabou reverberando nas ações desenvolvidas pelo Governo Dilma. As deliberações da III CNE, em 2010, orientaram, por exemplo, as mudanças na estrutura do ME, o desenvolvimento de ações previstas no Plano Plurianual 2012-2015 e as alterações na Lei Pelé (FLAUSINO, 2013) que, não obstante, acabaram por privilegiar o Esporte de Alto Rendimento (EAR) e a realização dos megaeventos esportivos. Em contrapartida, o Governo Dilma buscou estabelecer - a partir dos princípios da gestão democrática e da transparência - novos padrões de relacionamento entre o Governo Federal e as entidades de administração e de prática esportiva (clubes) (CARNEIRO, 2018).

\section{FONTES DE FINANCIAMENTO DO ESPORTE}

Ao longo de 2004 a 2015, o esporte teve $R \$ 29,69$ bilhões de recursos públicos federais (TRANSPARÊNCIA NO ESPORTE, 2019), os quais fazem parte da "matriz de financiamento público federal do esporte" (CARNEIRO et al., 2019c) e agregam orçamento, extraorçamento e gastos tributários. Sua distribuição pode ser observada na Figura 1:

Figura 1 - Fontes do financiamento público federal do esporte - série 2004-2015

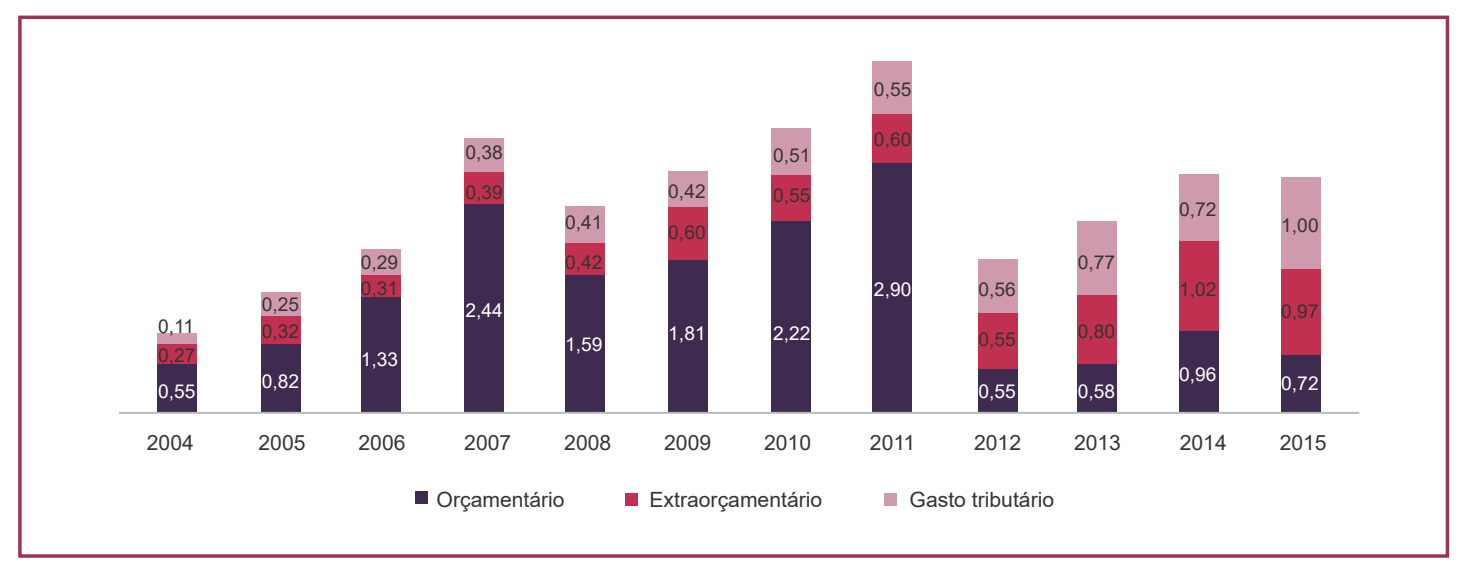

Fonte: Transparência no Esporte (2019). Elaboração própria.

Obs.: Valores deflacionados pelo IGP-DI a preços de dezembro de 2015 em R\$ bilhões

A Figura 1 em destaque aponta o crescimento das fontes de recursos para o esporte na comparação de 2015 com 2004, o que se justifica a partir da ampliação dos recursos extraorçamentários e dos gastos tributários. De acordo com Carneiro et al. (2019c), os Governos Lula e Dilma criaram diferentes legislações para ampliar as fontes de financiamento do esporte. Ademais, é importante assinalar que, enquanto no Governo Lula a fonte orçamentária foi a principal fonte de financiamento do esporte, no Governo Dilma as fontes prioritárias foram a extraorçamentária e os gastos tributários. Analisaremos cada uma das fontes a seguir.

\subsection{ORÇAMENTÁRIA}

A fonte orçamentária se refere aos recursos que passaram pelo orçamento público federal e foram direcionados ao esporte. No período analisado, tal fonte 
totalizou $\mathrm{R} \$ 16,48$ bilhões, isto é, $55,52 \%$ do total dos recursos. Contudo, este valor poderia ter chegado a $\mathrm{R} \$ 39,00$ bilhões. Isso porque, apenas $42,27 \%$ dos recursos autorizados foram liquidados (SENADO FEDERAL, 2019), indicando contingenciamento de recursos para a formação de superávit primário, garantindo o pagamento de juros e amortização da dívida pública (CARNEIRO, 2018). Uma série de estudos (SALVADOR, 2010; 2012; BEHRING, 2009; 2010) asserveram ser essa uma característica basilar do projeto neoliberal, isto é, a drenagem de recursos de políticas sociais para viabilizar a lucratividade via capital portador de juros que explora os títulos da dívida pública.

Dessa forma, a dívida pública constituiu num mecanismo de subtração do fundo público, comprimindo o orçamento (MASCARENHAS, 2016). Dessarte, o orçamento do esporte - a exemplo de diversas áreas sociais (SALVADOR, 2012) tem sido constrangido para realização dos interesses concretos de diversas frações burguesas que operam os títulos da dívida pública (VERONEZ, 2007; ATHAYDE, 2014a; ATHAYDE; MASCARENHAS; SALVADOR, 2015; MASCARENHAS, 2016; CASTRO 2016; CARNEIRO, 2018).

Dos $\mathrm{R} \$ 16,48$ bilhões, a maior parte foi alocada no $M E(R \$ 13,83$ bilhões) a partir da função "Desporto e Lazer". Contudo, outros órgãos federais direcionaram recursos para o esporte ( $R$ \$ 2,65 bilhões), sendo eles: o Ministério da Defesa (MD) - R\$ 1,49 bilhão; o Ministério da Educação (MEC) - R \$ 746,11 milhões; o Ministério da Cultura (MINC) - R \$408,71 milhões; e o Fundo Nacional para a Criança e o Adolescente (FNCA) - R\$ 8,20 milhões (TRANSPARÊNCIA NO ESPORTE, 2019).

O financiamento do MD estava atrelado à busca por reconhecimento do Esporte Militar, além de contribuir com a agenda dos Jogos Rio 2016 (GUIRRA; CASTELLANI FILHO, 2015). Já o MINC e o MEC tiveram recursos voltados à ampliação da infraestrutura esportiva e do acesso ao esporte como direito.

Outro elemento importante na disputa pelos recursos orçamentários foram as emendas parlamentares (TEIXEIRA et al., 2018), elas compuseram $47,88 \%$ dos recursos orçamentários (SENADO FEDERAL, 2019), tendo atendido interesses particularistas de deputados e senadores, garantindo recursos para suas bases políticas (TEIXEIRA, 2016). Para Teixeira (2016), o Governo Lula teve um número maior de emendas parlamentares no orçamento do ME, fato que explica a queda de recursos orçamentários a partir de 2012, já no Governo Dilma (TEIXEIRA, 2016; CARNEIRO, 2018).

O financiamento por recursos orçamentários se deu, no período analisado, principalmente por recursos ordinários - 85,19\% (SENADO FEDERAL, 2019) -, que são provenientes de Imposto de Renda (IR), Imposto sobre Produtos Industrializados (IPI) e desvinculação de recursos das Contribuições Sociais (SALVADOR, 2012) que, pelo caráter regressivo, sobrecarrega os trabalhadores. Outra fonte de financiamento importante do orçamento foram as contribuições sociais de loterias que representaram $10,18 \%$ do orçamento do esporte (SENADO FEDERAL, 2019), preservando, portanto, o caráter regressivo, uma vez que é a população de menor renda que consome este serviço (AMARAL, 2005). Os outros 4,63\% do orçamento do esporte é composto por recursos diversos: recursos para Manutenção e Desenvolvimento do Ensino, Salário- 
Educação, Contribuição Social sobre Lucro Líquido, remuneração das disponibilidades do Tesouro Nacional e doações privadas (SENADO FEDERAL, 2019).

\subsection{EXTRAORÇAMENTÁRIA}

Outra fonte de recurso para o esporte é a extraorçamentária que está relacionada aos recursos que não transitam pelo orçamento público federal. Seu total, no período analisado, foi de $R \$ 6,92$ bilhões (23,31\% do volume de recursos). A maior parte desta fonte foi de recursos de loterias repassadas pela Caixa Econômica Federal (CEF) para entidades esportivas ( $R$ \$ 3,43 bilhões) - Comitê Olímpicos Brasileiro (COB), clubes de futebol, Comitê Paralímpico Brasileiro (CPB) e Comitê Brasileiro de Clubes (CBC) - que receberam, respectivamente, $\mathrm{R} \$ 2,26$ bilhões, $\mathrm{R} \$ 631,73$ milhões, $\mathrm{R} \$ 395,41$ milhões e R\$ 182,96 milhões (TRANSPARÊNCIA NO ESPORTE, 2019).

O crescimento dos recursos extraorçamentários, nesse período, é fruto do aumento de repasses de loterias para entidades esportivas e do patrocínio de estatais. Os repasses de loterias para entidades esportivas aumentaram bastante ao longo do período, saltando de $\mathrm{R} \$ 175,72$ milhões, em 2004, para $\mathrm{R} \$ 472,33$ milhões, em 2015. Isso foi resultante do surgimento de novas loterias, como a Timemania e a Loteria Instantânea Exclusiva (CARNEIRO et al. 2019c).

Cabe destacar que os recursos direcionados pelo Estado para as entidades de administração esportivas e para os clubes são frutos da relação de longa data dessas entidades com o Governo Federal. Para Castellani Filho (2009), tal relação acabou por aprisionar o ME aos interesses das entidades de administração esportiva redundando no fortalecimento do EAR no âmbito do financiamento do esporte, influenciado diretamente a agenda esportiva brasileira para a realização dos megaeventos esportivos (MASCARENHAS et al. 2012).

Outra subfonte importante foi o patrocínio esportivo sem incentivo fiscal de estatais ( $R \$ 3,41$ bilhões). Não sendo inédito na história do esporte brasileiro, 13 estatais patrocinaram o esporte nacional no período estudado. Entre as mais importantes estiveram a CEF ( $R \$ 1,27$ bilhões), a Petrobras ( $R \$ 1,10$ bilhão), os Correios ( $R$ \$ 668,97 milhões) e a Eletrobrás ( $R$ \$ 300,63 milhões). As demais estatais patrocinaram R\$70,20 milhões (TRANSPARÊNCIA NO ESPORTE, 2019). Buscando ampliar o quantitativo de recursos para o EAR, foi lançado, pelo Governo Dilma, em 2013, o Plano Brasil Medalhas ${ }^{4}$, com significativa participação das estatais, cujo objetivo era ampliar os recursos com a finalidade de melhorar os resultados do país nos Jogos Rio 2016.

Os recursos de patrocínio das estatais para o esporte tiveram, portanto, grande crescimento ao longo do período analisado - saindo de $R \$ 93,01$ milhões, em 2004, para $\mathrm{R} \$ 501,20$ milhões, em 2015. O patrocínio das estatais ao esporte esteve diretamente associado ao interesse comercial destas instituições, utilizando o esporte como meio para melhorar a imagem em relação a seus consumidores. Além disso, de acordo com Pereira (2017), no Brasil, as estatais estão articuladas ao desenvolvimento de políticas públicas, tendo contribuído para o desenvolvimento de ações ligadas ao esporte ao longo dos Governos Lula e Dilma. No Governo Lula, 
observou-se, por exemplo, uma atuação forte das estatais na dinâmica da economia nacional (PEREIRA, 2017).

Ademais, esta fonte contou com recursos de contribuição sobre salários e transferências de atletas profissionais recebidos pela Federação das Associações de Atletas Profissionais (FAAP) - R\$ 76,95 milhões - e pela Federação Nacional dos Atletas Profissionais de Futebol (FENAPAF) - R\$ 0,51 milhão (TRANSPARÊNCIA NO ESPORTE, 2019).

\subsection{GASTOS TRIBUTÁRIOS}

Aúltima fonte é a de gastos tributários que envolvem recursos de desonerações e isenções fiscais para o esporte, com seu montante chegando a $R \$ 6,29$ bilhões ( $21,17 \%$ do total). Há, ainda, cinco subfontes diferentes no período, a saber: desoneração das entidades recreativas sem fins lucrativos ( $R$ \$ 3,04 bilhões); isenção de Imposto de Renda de Pessoa Física e Pessoa Jurídica para patrocínios e doações pela LIE (R\$ 2,08 milhões); desoneração para realização de megaeventos esportivos ( $R$ \$ 1,15 bilhão); isenção sobre equipamentos e materiais esportivos ( $R$ \$ 15,55 milhões); e isenção para eventos esportivos ${ }^{5}$ (R $\$$ 0,84 milhão) (TRANSPARÊNCIA NO ESPORTE, 2019).

Das cinco subfontes de gastos tributários, três foram criadas durante os Governos Lula e Dilma, ou seja, a LIE, a isenção para eventos esportivos e a desoneração para realização dos megaeventos esportivos. Destarte, o crescimento desta fonte de recurso se relaciona aos novos gastos tributários. No âmbito mais geral dos Governos Lula e Dilma, as desonerações tributárias se deram como elemento anticíclico para garantir que diferentes setores continuassem a reproduzir o capital, sobretudo no período póscrise econômica de 2008 (SINGER, 2015; PINTO et al., 2016). Contudo, no âmbito do esporte, as desonerações tributárias foram no sentido de garantir que o setor tivesse mais recursos, ou, ainda, oferecer as condições gerais de produção para que os megaeventos fossem realizados no país, tendo ocorrido garantias de que o Estado brasileiro cobriria os prejuízos, caso houvesse (MELO, 2011).

Ao longo de 2004 a 2015, a maior parte dos gastos tributários para o esporte incidiu sobre Imposto de Renda de Pessoa Jurídica (IRPJ) - 50,03\% de todo gasto tributário -, sobre Contribuição para o Financiamento da Seguridade Social (COFINS) - 31,62\% - e sobre Contribuição Social sobre Lucro Líquido (CSLL) 8,74\% (RECEITA FEDERAL DO BRASIL, 2019). Assim, os gastos tributários para o esporte contaram, sobretudo, com desonerações tributárias sobre as rendas do capital, além de impactarem recursos para a Seguridade Social.

A desoneração das entidades recreativas sem fins lucrativos atendeu diretamente os interesses do "terceiro setor", tendo recebido isenção fiscal para realização de políticas de esporte e lazer. Na LIE, a isenção de Pessoas Jurídicas representou $97,99 \%$ dos recursos, enquanto apenas 2,01\% foram de Pessoas Físicas.

5 Se refere a isenção na importação de bens e materiais recebidos no exterior ou distribuídos no país em eventos esportivos; nos materiais promocionais distribuídos/utilizados em evento esportivo oficial; e nos bens importados por desportistas que tenham sido utilizados em evento esportivo oficial e recebidos em doação de entidade de prática desportiva estrangeira ou da promotora ou patrocinadora do evento. 
Carneiro (2018) aponta que o setor financeiro foi um dos principais financiadores da LIE, contudo, outros setores foram importantes - o de mineração e de petróleo e gás, por exemplo.

\section{DIRECIONAMENTO DO GASTO COM ESPORTE}

Os recursos das diferentes fontes foram direcionados para diversas ações ao longo de 2004 a 2015. Estas estão agregadas em cinco diferentes categorias de gastos que tem sido utilizadas por diferentes estudos (MASCARENHAS, 2016; TEIXEIRA, 2016; PEREIRA, 2017; CARNEIRO 2018; TRANSPARÊNCIA NO ESPORTE, 2019), quais sejam: EAR; Esporte, Educação, Lazer e Inclusão Social (EELIS); Infraestrutura; Megaeventos; e Gestão. Na Figura 2, pode ser identificado o montante direcionado a cada uma destas categorias ao longo do período estudado.

Figura 2 - Direcionamento dos recursos públicos federais para o esporte - série 2004-2015

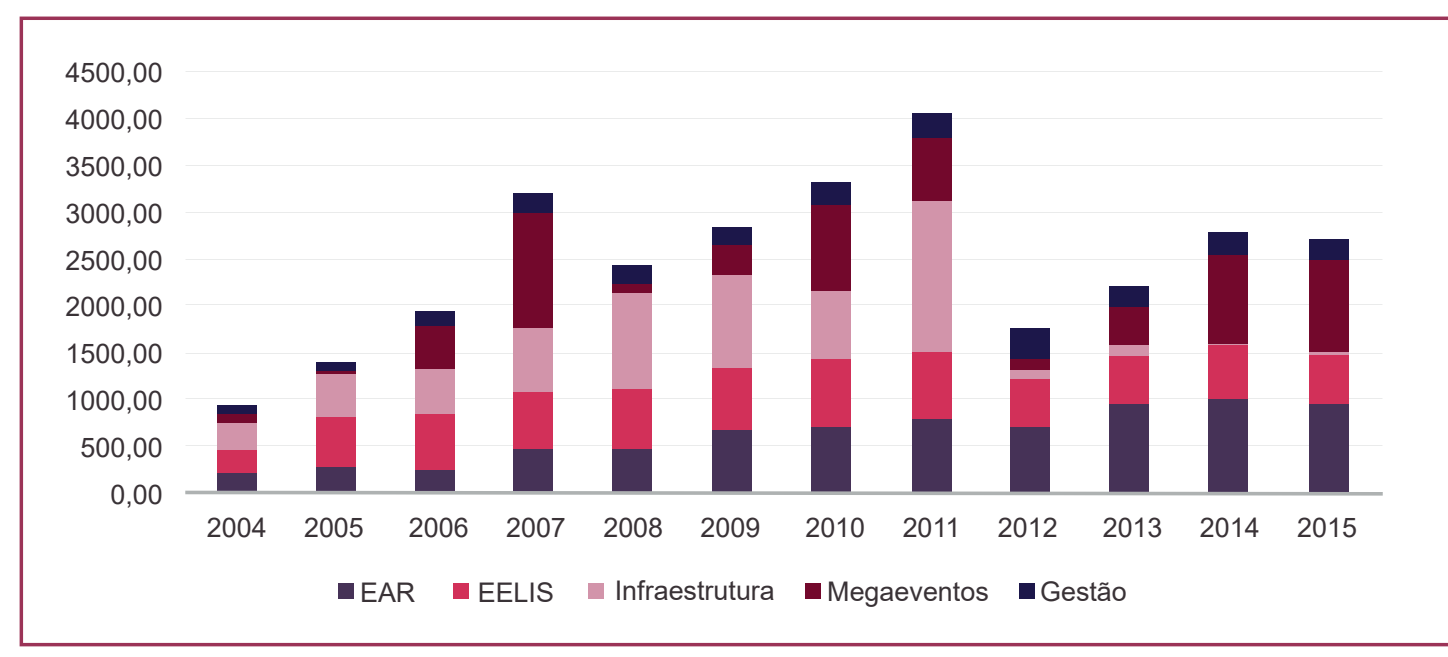

Fonte: Transparência no Esporte (2019). Elaboração própria.

Obs.: Valores deflacionados pelo IGP-DI a preços de dezembro de 2015 em R $\$$ milhões

\subsection{ESPORTE DE ALTO RENDIMENTO}

A categoria EAR está relacionada à preparação e participação de atletas em competições esportivas. Foi a categoria de gasto que teve mais recursos ( $R \$ 7,44$ bilhões $-25,08 \%$ do total). Tais recursos decorreram de: patrocínio das estatais (R\$ 2,59 bilhões), repasses de loterias para as entidades esportivas - COB, CPB, CBC e clubes de futebol - (R\$2,29 bilhões), da LIE (R\$ 1,39 bilhão), orçamento do ME ( $R$ \$ 1,00 bilhão), recursos da FAAP ( $R$ \$ 76,95 milhões), orçamento do MD ( $R$ \$ 74,14 milhões), isenção sobre equipamentos e materiais esportivos (R\$ 15,55 milhões), isenção para eventos esportivos ( $R$ \$ 0,84 milhão) e recursos da FENAPAF ( $R$ \$ 0,51 milhão).

Os recursos de EAR foram ampliando graças à criação de novos mecanismos de financiamento. Enquanto no Governo Lula o gasto médio com EAR em relação ao total de gasto foi de 19,23\%, no Governo Dilma esse percentual chegou a 34,34\%, o que representa o fortalecimento do EAR no âmbito dos recursos do esporte, elemento 
que tem relação direta com a realização dos megaeventos no Brasil. Na disputa pelos recursos para o esporte, as entidades de administração esportiva e os clubes se fortaleceram, pois ampliaram e diversificaram as suas fontes de financiamento (CARNEIRO et al., 2019c).

O MD passou, a partir de 2009, a disputar recursos orçamentários para alocar em EAR e Megaeventos. A presença do MD no esporte contribuía para os interesses políticos do ME, pois representou um aliado no Governo Federal para o desenvolvimento de políticas relacionadas ao EAR, e das entidades de administração esportiva, que viam a possibilidade do esporte militar contribuir com o fortalecimento do EAR e com a realização dos megaeventos (GUIRRA; CASTELLANI FILHO, 2015).

Assim, o EAR, por um lado, atendia aos interesses políticos do ME, do PCdoB, das entidades de administração esportiva, dos Governos Lula e Dilma e do PT, que buscaram associar a realização dos megaeventos às suas imagens. Por outro, o EAR respondia ao interesse social por bons resultados em competições internacionais, atendendo ao apelo ufanista e nacionalista da função de integração do Estado. O fortalecimento do EAR teve como resultado uma maior visibilidade de atletas e competições esportivas, em que o resultado foi a ampliação do esporte como negócio vinculado ao consumo.

Uma pequena parte do gasto com esporte nos Governos Lula e Dilma foram para FAAP e FENAPAF - instituições que atendiam interesses sociais de atletas e exatletas dada sua perspectiva de assistência social e educacional (CARNEIRO, 2018).

\subsection{ESPORTE, EDUCAÇÃO, LAZER E INCLUSÃO SOCIAL}

EELIS é a categoria que se articula às políticas de esporte como direito social. Seus recursos foram de $\mathrm{R} \$ 6,98$ bilhões $(23,51 \%$ do total). Fizeram parte da referida categoria os recursos de desoneração das entidades recreativas sem fins lucrativos (R\$ 3,04 bilhões); do ME (R\$ 2,26 bilhões); da LIE (R\$ 684,54 milhões); do patrocínio das estatais ( $R$ \$ $R \$ 524,61$ milhões); do COB, CPB e CBC para a Confederação Brasileira de Desporto Universitário (CBDU) e a Confederação Brasileira de Desporto Escolar (CBDE) (R\$ 376,88 milhões); do MEC (R\$ 87,17 milhões); e do FNCA (R\$ 8,20 milhões).

No período dos PPAs 2004-2007 e 2008-2011, os programas sociais esportivos, Programa Segundo Tempo e Programa Esporte e Lazer da Cidade, contavam com mais recursos que o EAR. Tal processo se inverte no PPA 2012-2015 em que a centralidade foi deslocada para o EAR e os Megaeventos (ATHAYDE, 2014a). O ME, órgão que deveria ser o grande articulador e organizador das políticas esportivas em prol da concretização do direito ao esporte, perdeu a centralidade de gasto com EELIS. Nesse sentido, outros interesses acabaram captando a agenda e os gastos do ME. O MEC, o MINC e o FNCA também contribuíram com os interesses sociais de promover políticas direcionadas ao atendimento do direito ao esporte de 2005 a 2009 .

Assim, ao longo do tempo, com orçamento reduzido, na disputa pelo orçamento público, o direito ao esporte foi colocado para escanteio, fragilizando a possibilidade 
de acesso universal do esporte pelo conjunto da população brasileira (CARNEIRO et al., 2019a).

Ao longo dos 12 anos analisados, o "terceiro setor" foi o que mais se beneficiou dos gastos com EELIS, pois contou com desonerações de diversas entidades sem fins lucrativos. Estas instituições realizaram suas ações esportivas sem controle social e sem atender uma política esportiva direcionada. Na aparência, o "terceiro setor" se mostrou como de interesse social, na medida em que realizou ações esportivas pautadas no discurso da solidariedade e da boa vontade. Contudo, interesses políticos de desresponsabilização do Estado acabaram promovendo uma ação focalizada, sobretudo, na juventude pobre (MELO, 2005).

Outras instituições que disputaram os recursos de EELIS foram a CBDU e a CBDE, estas se aliaram às entidades de administração esportiva, sobretudo, $\mathrm{COB}, \mathrm{CPB}$ e $\mathrm{CBC}$. Aquelas, a partir de recursos que seriam geridos por estas, desenvolveram ações para o esporte escolar e o esporte universitário. A referida vinculação fez com que muitas vezes as ações desenvolvidas pela CBDU e CBDE se aproximassem mais do EAR do que de EELIS, exemplo disso foram o formato das competições esportivas que promoveram (CARNEIRO, 2018).

Empresas privadas e estatais direcionaram recursos para EELIS por meio de patrocínios com e sem incentivos fiscais. Estas empresas, sob o discurso da chamada "responsabilidade social", buscam atrelar sua imagem ao esporte com fim de obter melhores resultados no mercado.

\subsection{INFRAESTRUTURA ESPORTIVA}

O terceiro maior direcionamento de recursos foi para Infraestrutura esportiva ( $R$ \$ 6,52 bilhões, 21,94\% do total). Essa categoria se refere à reforma e construção de instalações esportivas, exceto para a realização dos Megaeventos. O ME gastou no período analisado $\mathrm{R} \$ 5,45$ bilhões, também gastaram com Infraestrutura esportiva o MEC (R\$ 658,94 milhões) e o MINC (R\$ 408,71 milhões) (TRANSPARÊNCIA NO ESPORTE, 2019). Desses recursos, R $\$ 6,43$ bilhões foram para Infraestrutura de EELIS e R\$ 81,17 milhões para Infraestrutura de EAR (TRANSPARÊNCIA NO ESPORTE, 2019).

Conforme a Figura 2, a maior parte do gasto com Infraestrutura se deu entre 2008 e 2011. Nesse período, foram gastos $\mathrm{R} \$ 4,40$ bilhões, o que representa $67,50 \%$ de todo o gasto com a categoria. A partir de 2006-2007, a ascensão da economia mundial e melhoria das contas externas do país possibilitaram o aumento do investimento em Infraestrutura (MASCARENHAS, 2016). Este processo se articulava também ao arranjo político e econômico do bloco no poder, com forte presença das empresas vinculadas ao setor da construção civil.

O investimento em Infraestrutura esportiva associou a interesses econômicos, políticos e sociais da construção civil. De acordo com Athayde (2014b) e Filgueiras e Gonçalves (2007), a construção civil foi uma das principais patrocinadoras das campanhas eleitorais de Lula e Dilma. 
Ademais, os recursos direcionados para Infraestrutura estiveram conectados aos interesses econômicos, políticos e sociais do PT (CARNEIRO, 2018). Os interesses econômicos se associavam a retribuir seus patrocinadores, e também promover uma política de investimento pautado no (neo)desenvolvimentismo. Politicamente era interessante ter obras espalhadas pelo país, além de contribuir com a melhoria nos dados econômicos. Os interesses sociais buscavam garantir que a União tivesse uma maior capilaridade pelo país, por meio de diferentes infraestruturas, dentre elas as esportivas.

Além disso, o investimento em Infraestrutura esportiva atendeu ao interesse político de parlamentares que se utilizaram de emendas para a construção e reforma de equipamentos esportivos nas suas bases eleitorais, obtendo, assim, representação material do seu poder político. Esse processo se articulou a interesses clientelistas que fizeram parte da trajetória política do país (TEIXEIRA, 2016).

Para Mascarenhas (2008, p. 106), o gasto estatal com infraestrutura combina dois movimentos: "[...] por um lado, a criação da estrutura para atender a essa lógica do esporte enquanto negócio [...]; e, por outro lado, tal criação/construção de infraestrutura vem combinada com a nossa tradição clientelista [...]". A forma como se deu o gasto com Infraestrutura, reforça o papel do Estado investidor no esporte, sendo seus "negócios" o foco.

\subsection{MEGAEVENTOS ESPORTIVOS}

O gasto com Megaeventos esportivos foi a quarta maior categoria de gasto ( $R \$ 6,40$ bilhões, representando $21,56 \%$ do total), se referindo a recursos para diferentes Megaeventos. O que recebeu mais recursos foram os Jogos Rio 2016 (R\$ 2,52 bilhões). Tal montante foi proveniente do orçamento do $M E$ ( $R$ \$ 1,58 bilhão), de desonerações tributárias ( $R$ \$ 674,76 milhões) e de patrocínio das estatais ( $R$ \$ 263,89 milhões). O segundo que teve mais recursos foram os Jogos Pan Rio 2007 ( $R$ \$ 1,82 bilhão), advindos do $M E$ ( $R \$ 1,79$ bilhão) e de patrocínio das estatais (22,96 milhões). O terceiro, os Jogos Mundiais Militares 2011 ( $R$ \$ 1,42 bilhão), tendo sido R\$ 1,42 bilhão do MD e R\$2,91 milhões de patrocínio das estatais. Por último, os gastos com a Copa do Mundo FIFA 2014 (R\$ 644,09 milhões), dos quais R\$ 166,93 milhões saíram do ME e R \$ 477,17 milhões de desonerações tributárias.

Os Megaeventos se tornaram o princípio organizador da agenda esportiva brasileira (MASCARENHAS et al., 2012; FLAUSINO, 2013), tendo sido alçados à prioridade do ME no segundo mandato do Governo Lula (ATHAYDE, 2014b) e no Governo Dilma (CARNEIRO et al., 2019a). Na III CNE, no PDEL e no PPA 2012-2015 ficou claro que a prioridade eram os Megaeventos e o fortalecimento do EAR, fato que se verificou no financiamento e gasto com esporte.

Portando, os Megaeventos atenderam interesses econômicos e políticos dos Governos Lula e Dilma, tendo envolvido institucionalmente e com recursos, o $\mathrm{ME}, \mathrm{o} \mathrm{MD}$ e as estatais. O Estado brasileiro possibilitou a garantia das condições gerais de produção para os Megaeventos, expressão disso foram as desonerações tributárias para a realização da Copa FIFA 2014 e os Jogos Rio 2016, além de terem fornecido financiamento de bancos públicos para a construção de infraestrutura 
esportiva. Desse modo, o Estado brasileiro se fez presente como financiador e investidor (MASCARENHAS et al., 2012). Dessarte, os megaeventos esportivos se tornaram uma política do Estado brasileiro, vez que envolveu diferentes instâncias governamentais (SANTOS JÚNIOR; LIMA, 2015).

Mascarenhas et al. (2012), Castellani Filho (2014) e Guirra e Castellani Filho (2015) apontam que o Estado brasileiro acabou se subordinando aos interesses do COI e do COB para que os Jogos Rio 2016 fossem realizados, e o mesmo teria se dado em relação à FIFA e à CBF para a concretização da Copa do Mundo FIFA 2014. As entidades de administração esportiva conseguiram estabelecer uma imbricada articulação com o Governo brasileiro, possibilitando o fortalecimento do EAR e trazendo ao primeiro plano da agenda estatal os megaeventos esportivos. Isso possibilitou que se tornassem uma das instituições mais fortes na disputa pelo financiamento e gasto com esporte durante os Governos Lula e Dilma.

Os Megaeventos eram uma justificativa para que o processo de acumulação de capital fosse ampliado em nosso país, tendo sido uma parte central das estratégias para obtenção de consenso por uma parte considerável do bloco no poder no país (GAWRYSZEWSKI; PENNA; MELO, 2015). Diferentes setores da economia se beneficiaram da realização dos Megaeventos esportivos, isto é, a construção civil, o setor bancário-financeiro, o turismo, o imobiliário, a indústria bélica, a aviação, o setor de alimentos e bebidas, etc. (CARNEIRO, 2018).

\subsection{GESTÃO}

A categoria de gasto com menos recursos foi a de Gestão ( $R$ \$ 2,35 bilhões, representando $7,91 \%$ do total). Este gasto esteve vinculado à manutenção e gestão das instituições responsáveis pelas políticas esportivas - ME (R\$ 1,58 bilhão), COB ( $R$ \$ 610,93 milhões), CPB ( $R$ \$ 118,62 milhões) e CBC ( $R$ \$ 36,59 milhões) - e gasto de patrocínio das estatais ( $R \$ 5,54$ milhões) para eventos sobre esporte e publicidade esportiva.

Há também os recursos de gestão que foram disputados pelo ME, COB, $\mathrm{CPB}, \mathrm{CBC}$ e empresas estatais. Os interesses presentes na disputa pelo gasto com Gestão são predominantemente políticos, embora haja interesses dos trabalhadores para que os órgãos públicos ofereçam atendimento qualificado. Na medida em que é o órgão que realiza a Gestão das políticas esportivas em âmbito nacional, o ME foi a instituição que mais recursos obteve dessa categoria.

No que tange às entidades de administração esportiva, o Tribunal de Contas da União (2014) apontou que existe uma grande dependência do COB, do CPB, do $C B C$, da CBDE, da CBDU e das confederações olímpicas e paralímpicas em relação aos recursos públicos, sendo que grande parte deles são direcionados para atividades-meio (Gestão), dependendo sua sobrevivência dos recursos públicos.

\section{CONSIDERAÇÕES FINAIS}

Pelo apresentado até aqui, há interesses econômicos, políticos e sociais envolvidos na disputa pelo financiamento e pelo gasto com o esporte durante os 
Governos Lula e Dilma. No financiamento do esporte, o maior volume foi da fonte orçamentária que, não obstante, atendeu interesses do capital financeiro, dos parlamentares e dos diferentes órgãos que direcionaram recursos ao esporte (ME, MD, MEC, MINC e FNCA).

Observou-se, ainda, o crescimento das fontes extraorçamentárias e de gastos tributários, haja vista uma indução dos Governos Lula e Dilma para fortalecer os recursos de loterias para o esporte e do patrocínio das estatais. Os recursos extraorçamentários atenderam principalmente interesses das entidades de administração esportiva, das estatais e dos clubes esportivos, já os gastos tributários atenderam interesses do "terceiro setor", das empresas privadas (setor bancáriofinanceiro e produtivo), das entidades de administração esportiva, dos clubes, etc.

O financiamento do esporte nos Governos Lula e Dilma teve um caráter regressivo no orçamento e nos gastos tributários, situando o âmbito do esporte como expressão de realização dos interesses do conjunto da classe burguesa nacional e internacional. A despeito da luta de setores muito minoritários pelo direito ao esporte, a análise do acesso ao fundo público mostra uma subordinação ao projeto burguês expressa na contraditória configuração das ações desenvolvidas pelos governos do PT.

O direcionamento do gasto com esporte contou com certa equidade entre as categorias EAR, EELIS, Infraestrutura e Megaeventos. Contudo, ao longo do tempo foram fortalecidos os interesses envolvidos no EAR e nos Megaeventos. Estes foram alçados ao primeiro plano da política esportiva - também da política mais ampla dos Governos Lula e Dilma -, materializando os interesses e projetos da classe dominante expressos na atuação estatal, das entidades nacionais e internacionais de administração esportiva e outras frações burguesas nacionais e internacionais. Os interesses econômicos e políticos se fizeram bastante presente nos Megaeventos e na Infraestrutura esportiva. Os interesses vinculados a EELIS, isto é, a garantia do esporte como direito ficaram secundarizados, tendo sido implementados, principalmente, pelo "terceiro setor". No setor esportivo, a fração que ficou mais fortalecida ao longo dos Governos Lula e Dilma foi das entidades de administração esportiva.

Por isso, é possível afirmar que, nos Governos Lula e Dilma, o esporte - sem abandonar a função integradora - passou a ter um papel importante na garantia das condições gerais de produção e reprodução do capital, por meio do aporte expresso do fundo público na direção contrária ao fortalecimento do direito ao esporte.

Pelo exposto, em um momento de crise estrutural do capitalismo, o esporte foi um dos elementos anticíclicos utilizados, haja vista os investimentos em Infraestrutura esportiva e os gastos com Megaeventos. Além disso, participou diretamente da perspectiva (neo)desenvolvimentista dos Governos Lula e Dilma.

Nesses termos, a Figura 3 expressa uma síntese e oferece uma representação panorâmica dos diferentes agentes e instituições que disputaram os recursos do financiamento e do gasto com esporte ao longo de 2004 a 2015. 
Figura 3 - A disputa pelo financiamento e gasto com esporte nos Governos Lula e Dilma

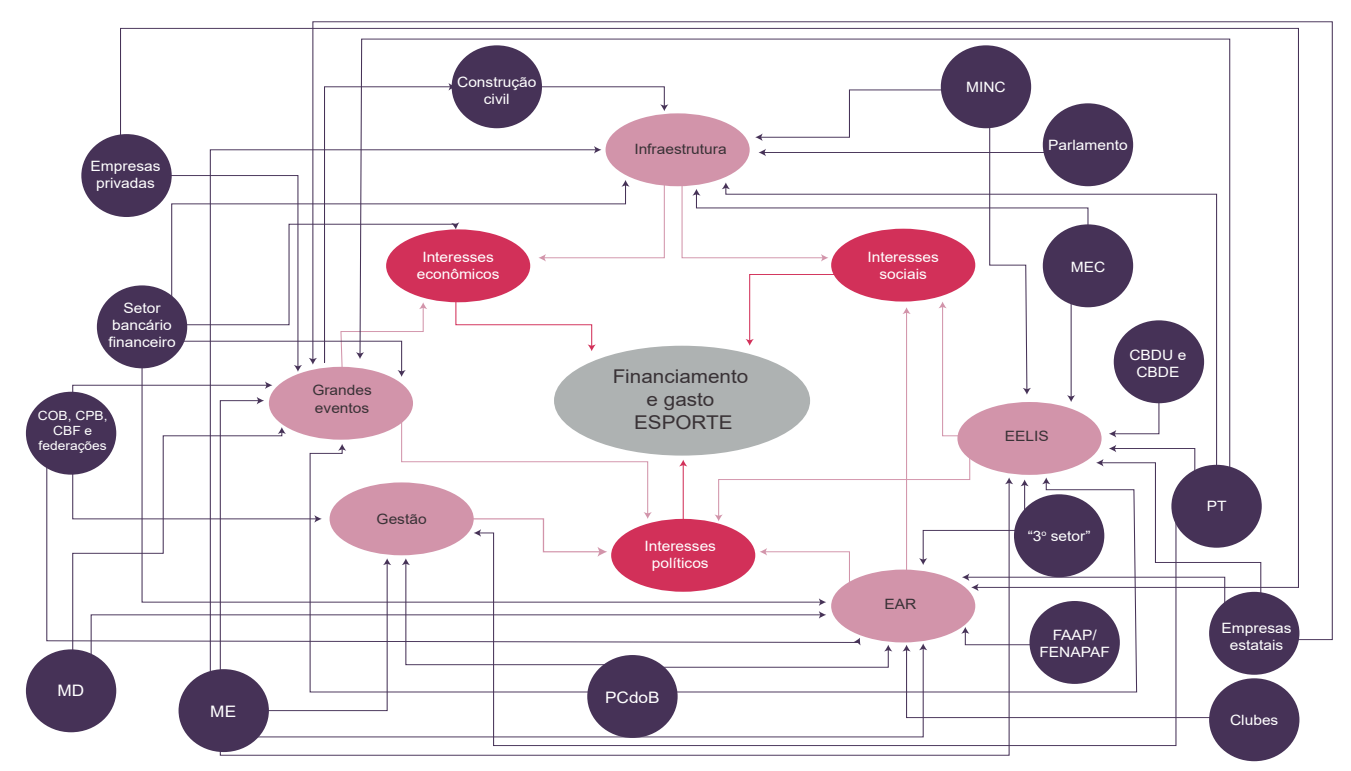

Fonte: Elaboração própria

Por fim, cabe apontar que o financiamento da política esportiva nos Governos Lula e Dilma sinaliza o atendimento prioritário dos interesses econômicos e políticos, em detrimento dos interesses sociais. Assim, é preciso continuar lutando por políticas de esporte que sejam democráticas e atendam a interesses sociais mais amplos. Para que isto ocorra, uma importante bandeira se relaciona com a disputa pelo financiamento e pelo gasto com esporte.

\section{REFERÊNCIAS}

AMARAL, José Ronaldo do. As loterias federais brasileiras: um estudo da arrecadação e de sua previsão. 2005. Dissertação (Mestrado em Economia do Setor Público) Universidade de Brasília, Brasília, 2005.

ANDERSON, Perry. O Brasil de Lula. Novos Estudos, n. 91, p. 23-52, nov. 2011.

ATHAYDE, Pedro Fernando Avalone. A disputa pelo fundo público no âmbito do financiamento esportivo brasileiro. Revista Brasileira de Ciências do Esporte, v. 36, n. 2, supl., p. S636-S651, abr./jun. 2014a.

ATHAYDE, Pedro Fernando Avalone. O ornitorrinco de chuteiras: determinantes econômicos da política de esporte e lazer do governo Lula e suas implicações sociais. 2014. Tese (Doutorado em Política Social) - Universidade de Brasília, Brasília, 2014b.

ATHAYDE, Pedro Fernando Avalone; MASCARENHAS, Fernando; SALVADOR, Evilasio. Primeiras aproximações de uma análise do financiamento da política nacional de esporte e lazer no governo Lula. Revista Brasileira de Ciências do Esporte, v. 37, n. 1, p. 2-10, jan./mar. 2015.

BEHRING, Elaine Rossetti. Acumulação capitalista, fundo público e política social. In: BEHRING, Elaine Rossetti et al. (Orgs.). Política social no capitalismo: tendências contemporâneas. 2. ed. São Paulo: Cortez, 2009. p. 44-63. 
BEHRING, Elaine Rossetti. Crise do capital, fundo público e valor. In: BEHRING, Elaine Rossetti et al.. (Orgs.). Capitalismo em crise, política social e direitos. São Paulo: Cortez, 2010. p. 13-34.

BOITO JÚNIOR, Armando. As bases políticas do neodesenvolvimentismo. Trabalho apresentado na edição de 2012 do Fórum Econômico da FGV/São Paulo. 2012. Disponível em: http://bibliotecadigital.fgv.br/dspace/bitstream/handle/10438/16866/Painel\%203\%20 -\%20Novo\%20Desenv\%20BR\%20-\%20Boito\%20-\%20Bases\%20Pol\%20Neodesenv $\% 20$ -\%20PAPER.pdf?sequence=1. Acesso em: 21 out. 2019.

BOITO JÚNIOR, Armando. A burguesia brasileira no golpe do impeachment. Brasil de Fato, São Paulo, 6 jan. 2017. Disponível em: https://www.brasildefato.com.br/2017/01/06/aburguesia-brasileira-no-golpe-do-impeachment/. Acesso em: 21 out. 2019.

BRASIL. Lei $\mathbf{n}^{\circ} 10.933$, de 11 de agosto de 2004. Plano Plurianual para o período 2004/2007. 2004. Disponível em: http://www.planalto.gov.br/ccivil_03/_ato2004-2006/2004/ lei/l10.933.htm. Acesso em: 21 out. 2019.

BRASIL. Lei $\mathbf{n}^{0}$ 11.653, de 07 de abril de 2008. Plano Plurianual para o período 2004/2007. 2008. Disponível em: http://www.planalto.gov.br/ccivil_03/_ato2007-2010/2008/ lei/l11653.htm. Acesso em: 21 out. 2019.

BRASIL. Lei n ${ }^{\circ} 12.593$, de 18 de janeiro de 2012. Plano Plurianual da União para o período de 2012 a 2015. 2012. Disponível em: http://www.planalto.gov.br/ccivil 03/ ato20112014/2012/Lei/L12593.htm. Acesso em: 21 out. 2019.

CARNEIRO, Fernando Henrique Silva. O financiamento do esporte no Brasil: aspectos da atuação estatal nos governos Lula e Dilma. 2018. Tese (Doutorado em Educação Física) - Universidade de Brasília, Brasília, 2018.

CARNEIRO, Fernando Henrique Silva; MASCARENHAS, Fernando. O financiamento esportivo brasileiro: proposta de metodologia crítica de análise. E-legis, Brasília, v. 11, n. especial, p. 119-140, nov. 2018.

CARNEIRO, Fernando Henrique Silva; ATHAYDE, Pedro Fernando Avalone; MASCARENHAS, Fernando. Era uma vez um ministério do esporte...: seu financiamento e gasto nos governos Lula, Dilma e Temer. Motrivivência, v. 31, n. 60, p. 1-22, nov. 2019.

CARNEIRO, Fernando Henrique Silva, et al.. Orçamento do esporte no governo Dilma: a primazia dos interesses econômicos e o direito escanteado. Revista Brasileira de Ciências do Esporte, v. 41, n. 4, p. 343-349, out./dez. 2019a.

CARNEIRO, Fernando Henrique Silva, et al.. Os gastos tributários com esporte nos Governos Lula e Dilma. Movimento, v. 25, e25059, p. 1-14, jan./dez. 2019 b.

CARNEIRO, Fernando Henrique Silva, et al.. A matriz de financiamento público federal do esporte no Brasil. Revista Brasileira de Ciência e Movimento, v. 27, n. 4, p. 85-102, out./ dez. 2019c.

CASTELLANI FILHO, Lino. O PT, a política esportiva brasileira e a síndrome de Estocolmo. Campinas, 2009. Disponível em: http://observatoriodoesporte.org.br/o-pt-apolitica-esportiva-brasileira-e-a-sindrome-de-estocolmo. Acesso em: 21 out. 2009.

CASTELLANI FILHO, Lino. Megaeventos esportivos no Brasil: de expressão da política esportiva brasileira para a da concepção neodesenvolvimentista de planejamento urbano. Motrivivência, v. 26, n. 42, p. 98-114, jun. 2014. 
CASTRO, Suélen Barboza Eiras de. Políticas públicas para o esporte e lazer e o ciclo orçamentário brasileiro (2004-2011): prioridades e distributição de recursos durante os processos de elaboração e execução orçamentária. 2016. Tese. (Doutorado em Educação Física) - Universidade Federal do Paraná, Curitiba, 2016.

COUTINHO, Carlos Nelson. A hegemonia da pequena política. In: OLIVEIRA, Francisco de; BRAGA, Ruy; RIZEK, Cibele. (Orgs.). Hegemonia às avessas. São Paulo: Boitempo, 2010. p. 29-46.

FILGUEIRAS, Luiz Antônio Mattos; GONÇALVES, Reinaldo. A economia política do governo Lula. Rio de Janeiro: Contraponto, 2007.

FLAUSINO, Michelle da Silva. Plano Decenal: as políticas públicas de esporte e lazer em jogo. 2013. Dissertação (Mestrado em Educação Física) - Universidade de Brasília, Brasília, 2013.

GAWRYSZEWSKI, Bruno; PENNA, Adriana Machado; MELO, Marcelo Paula de. Megaeventos esportivos e indústria bélica: expressões do capitalismo contemporâneo. Trabalho Necessário, ano 13, n. 21, p. 165-196, 2015.

GUIRRA, Frederico Jorge Saad; CASTELLANI FILHO, Lino. V Jogos Mundiais Militares no Brasil: o esporte militar a serviço da agenda Rio-2016. In: CONGRESSO BRASILEIRO DE CIÊNCIAS DO ESPORTE (CONBRACE) E V CONGRESSO INTERNACIONAL DE CIÊNCIAS DO ESPORTE (CONICE).19. 2015, Vitória. Anais...Vitória: 2015. p. 1-16. Disponível em: http://congressos.cbce.org.br/index.php/conbrace2015/6conice/paper/ download/6831/3438. Acesso em: 21 out. 2019.

MASCARENHAS, Fernando. O orçamento do esporte: aspectos da atuação estatal de FHC a Dilma. Revista Brasileira de Educação Física e Esporte, v. 30, n. 4, p. 963-980, out./ dez. 2016.

MASCARENHAS, Fernando. O Estado brasileiro e os direitos sociais: o lazer. In: GARCIA, Carla Cristina; HÚNGARO, Edson Marcelo; DAMASCENO, Lucianos Galvão. Estado, política e emancipação humana: lazer, educação, esporte e saúde como direitos sociais. Santo André: Alpharrabio, 2008. p. 95-114.

MASCARENHAS, Fernando et al.. O Bloco Olímpico: Estado, organização esportiva e mercado na configuração da agenda Rio 2016. Revista da ALESDE, v. 2, n. 2, p. 15-32, out. 2012.

MATIAS, Wagner Barbosa et al.. A Lei de Incentivo Fiscal e o (não) direito ao esporte no Brasil. Movimento, v. 21, n. 1, p. 95-110, jan./mar. 2015.

MELO, Marcelo Paula de. Esporte e juventude pobre: políticas públicas de lazer na Vila Olímpica da Maré. Campinas, SP: Autores Associados, 2005. (Coleção Educação Física e Esportes).

MELO, Marcelo de Paula. Esporte e dominação burguesa no século XXI: a agenda dos organismos internacionais e sua incidência nas políticas de esporte no Brasil. 2011. Tese (Doutorado em Serviço Social) - Universidade Federal do Rio de Janeiro, Rio de Janeiro, 2011.

OLIVEIRA, Francisco de. Hegemonia às avessas. In: OLIVEIRA, Francisco de; BRAGA, Ruy; RIZEK, Cibele. (Orgs.). Hegemonia às avessas. São Paulo: Boitempo, 2010. p. 21-28.

PEREIRA, Claudia Catarino. As empresas estatais e o financiamento do esporte nos governos Lula e Dilma. 2017. Dissertação (Mestrado em Educação Física) - Universidade de Brasília, Brasília, 2017. 
PINTO, Eduardo Costa. Dilma: de "coração valente" à "presidenta acuada". In: PINTO, Eduardo Costa; FIGUEIRAS, Luiz; GONÇALVES, Reinaldo. Governo Dilma, PT, esquerda e impeachment: Três interpretações da conjuntura econômica e política. UFRJ, Instituto de Economia. Texto para Discussão 015. set. 2015. Disponível em: http://www.ie.uffi.br/images/ pesquisa/publicacoes/discussao/2015/TD IE 0152015 PINTO FILGUEIRAS GONALVES.pdf. Acesso em: 15 out. 2019.

PINTO, Eduardo Costa; GONÇALVES, Reinaldo. Modelos de desenvolvimento e desempenho macroeconômico: Brasil. UFRJ, Instituto de Economia. Texto para Discussão 017. out. 2015. Disponível em: http://www.ie.ufrj.br/images/pesquisa/publicacoes/ discussao/2015/TD_IE_017_2015_PINTO_GONALVES.pdf. Acesso em: 21 out. 2019.

PINTO, Eduardo Costa et al.. A economia política dos governos Dilma: acumulação, bloco no poder e crise. UFRJ, Instituto de Economia. Texto para Discussão 004, 2016. Disponível em: http://www.ie.ufrj.br/images/pesquisa/publicacoes/discussao/2016/TD IE_004_2016_COSTA_PINTO_et_al.pdf. Acesso em: 21 out. 2019.

\section{RECEITA FEDERAL DO BRASIL. Demonstrativos dos Gastos Tributários Bases}

Efetivas. 2019. Disponível em: http://receita.economia.gov.br/dados/receitadata/renunciafiscal/demonstrativos-dos-gastos-tributarios/dgt-bases-efetivas. Acesso em: 20 ago. 2019.

SADER, Emir (Org.). 10 anos de governos pós-neoliberais no Brasil: Lula e Dilma. São Paulo: Boitempo; Rio de Janeiro: FLACSO Brasil, 2013.

SALVADOR, Evilásio. Crise do capital e o socorro do fundo público. In: BOSCHETTI, Ivanetti et al.. (Orgs.). Capitalismo em crise, política social e direitos. São Paulo: Cortez, 2010. p. 35-63.

SALVADOR, Evilasio. Financiamento tributário da política social no pós-Real. In: SALVADOR, Evilasio et al. (Orgs.). Financeirização, fundo público e política social. São Paulo: Cortez, 2012. p. 123-152.

SANTOS JÚNIOR, Orlando Alves dos; LIMA, Caio Guimarães Rocha. Impactos Econômicos dos Megaeventos no Brasil: investimento público, participação privada e difusão do empreendedorismo urbano neoliberal. In: SANTOS JÚNIOR, Orlando Alves dos; GAFFNEY, Christopher; RIBEIRO, Luiz Cesar de Queiroz (Orgs.). Brasil: os impactos da Copa do Mundo 2014 e das Olimpíadas. Rio de Janeiro: E-papers, 2015, p. 57-77.

SENADO FEDERAL. SIGA Brasil. 2019. Disponível em: https://www12.senado.leg.br/ orcamento/sigabrasil. Acesso em: 17 out. 2019.

SINGER, André. Será o lulismo um reformismo fraco? In: Os sentidos do lulismo: reforma gradual e pacto conservador. São Paulo: Companhia das Letras, 2012. p.169-221.

SINGER, André. Raízes sociais e ideológicas do lulismo. Novos Estudos, n. 85, p. 83-102, nov. 2009.

SINGER, André. Cutucando onças com varas curtas: o ensaio desenvolvimentista no primeiro mandato de Dilma Rousseff (2011-2014). Novos Estudos, n. 102, p. 43-71, jul. 2015.

TRIBUNAL DE CONTAS DA UNIÃO. Relatório de levantamento de auditoria: Sistema Nacional do Desporto. TC 021.654/2014-0. 2014. Disponível em: https://contas.tcu.gov.br/ egestao/ObterDocumentoSisdoc?codArqCatalogado=9120982. Acesso em: 02 jun. 2018.

TEIXEIRA, Marcelo Resende. Esporte, fundo público e pequena política: os reveses de um orçamento (r)emendado. 2016. Dissertação (Mestrado em Educação Física) Universidade de Brasília, Brasília, 2016. 
TEIXEIRA, Marcelo Resende et al.. Esporte, fundo público e pequena política: os reveses de um orçamento (R)emendado. Movimento, v. 24, n. 2, p. 593-606, abr./jun. de 2018.

TRANSPARÊNCIA NO ESPORTE. Recursos para o esporte. Brasília, 2019. Disponível em: http://www.transparencianoesporte.unb.br. Acesso em: 17 out. 2019.

VERONEZ, Luiz Fernando Camargo. O planejamento governamental e o orçamento do setor esportivo. In: CONGRESSO BRASILEIRO DE CIÊNCIAS DO ESPORTE, 15.; CONGRESSO INTERNACIONAL DE CIÊNCIAS DO ESPORTE, 2., 2007, Recife. Anais.. Goiânia: CBCE, 2007. Disponível em: http://www.cbce.org.br/docs/cd/resumos/275.pdf. Acesso em: 20 dez. 2019. 
Abstract: This article aimed to understand the dispute for public funds in sports financing and spending during the Lula da Silva and Rousseff administrations. The qualitative research was supported by document survey on funding sources and the type of spending on sports from 2004 to 2015. The information was collected online from Transparência no Esporte, SIGA Brasil, and the Brazilian Revenue Service's Demonstrativos dos Gastos Tributários de Bases Efetivas. The data indicate that funding and spending on sports in the Lula da Silva and Rousseff administrations involved different economic, social and political interests, which in turn were linked to different sources of funding - budget, extra-budget and tax expenditures - and influenced the type of spending - High Performance Sports; Sports, Education, Leisure and Social Inclusion; Infrastructure; Mega Sporting Events; and Management.

Keywords: State. Public policy. Financing, government. Cost transparency.

Resumen: Este artículo tuvo como objetivo comprender la disputa por el fondo público en el ámbito de la financiación y el gasto con deportes en los Gobiernos de Lula y Dilma. La investigación, cualitativa, fue respaldada por un estudio documental sobre las fuentes de financiación y la destinación del gasto con deportes de 2004 a 2015. Estas informaciones fueron recolectadas en el Portal Transparencia en el Deporte, en el SIGA Brasil y en los Demostrativos de los Gastos Tributarios de Bases Efectivas de la Hacienda de Brasil. Los datos indican que la financiación y el gasto con deportes en los gobiernos de Lula y Dilma involucraron diferentes intereses económicos, sociales y políticos, que, a su vez, estaban vinculados a diferentes fuentes de financiación (presupuesto, presupuesto extra y gastos tributarios) e influyeron en la destinación del gasto -Deporte de Alto Rendimiento; Deporte, Educación, Ocio e Inclusión Social; Infraestructura; Mega Eventos Deportivos y Gestión.

Palabras clave: Estado. Política pública. Financiación gubernamental. Transparencia de los gastos. 


\section{LICENÇA DE USO}

Este é um artigo publicado em acesso aberto (Open Access) sob a licença Creative Commons atribuição Não Comercial 4.0 (CC BY-NC 4.0), que permite uso, distribuição e reprodução em qualquer meio, desde que o trabalho original seja corretamente citado, com a restrição que impede o uso para fins comerciais. Mais informações em: http://creativecommons.org/licenses/by-nc/4.0

\section{CONFLITO DE INTERESSES}

Os autores declararam que não há conflito de interesses neste trabalho.

\section{DECLARAÇÃO DE APROVAÇÃO EM COMITÊ DE PESQUISA}

Não se aplica

\section{CONTRIBUIÇÕES DE AUTORIA}

Fernando Henrique Silva Carneiro: Coleta de dados, sistematização e organização dos dados e escrita do artigo.

Marcelo Paula de Melo: Análise dos dados, normalização do artigo e escrita do artigo.

Nadson Santana Reis: Análise dos dados, normalização do artigo e escrita do artigo.

Fernando Mascarenhas: Orientação da pesquisa, análise dos dados e escrita do artigo.

\section{FINANCIAMENTO}

Não houve financiamento por órgãos de fomento.

\section{COMO REFERENCIAR}

CARNEIRO, Fernando Henrique Silva; MELO, Marcelo Paula de; REIS, Nadson Santana; MASCARENHAS, Fernando. A disputa pelo fundo público no financiamento e gasto com esporte nos governos Lula e Dilma. Movimento, v. 26, p. e26056, jan./dez. 2020. Disponível em: https://seer.ufrgs.br/Movimento/ article/view/99241 Acesso em: 12 ago. 2020. DOI: https://doi.org/10.22456/1982$\underline{8918.9924}$

\section{RESPONSÁVEIS EDITORIAIS}

Alex Branco Fraga*, Elisandro Schultz Wittizorecki*, Ivone Job*, Mauro Myskiw*, Raquel da Silveira*

*Universidade Federal do Rio Grande do Sul, Escola de Educação Física, Fisioterapia e Dança, Porto Alegre, RS, Brasil 